\title{
COMMUNICATION AND THEIR ROLE IN THE PREPARATION AND PRESENTATION OF THE BASKETBALL REFEREE
}

\author{
Fabiana MARTINESCU-BĂDĂLAN \\ "Nicolae Bălcescu" Land Forces Academy, sibiu, Romania \\ martinescu_fabiana@yahoo.com
}

\begin{abstract}
The present paper wishes to start from the premise that we are preparing to express, namely that there is a correlation between the degree of preparation of the basketball referees and their results during the games, between their actual training and the performance we observe. The basketball referee is the person who judges all phases of the game, taking decisions in fractions of a second. For this the referee needs interdisciplinary training, yet not forgetting that he is often selftaught, learning and taking over from field specialists.
\end{abstract}

Keywords: communication, referee, language, preparation, basketball.

\section{Introduction}

Communication can be defined as: the whole process of exchanging information and meaning between people in a given social situation[1].

Communication in its essence means using certain communication methods: to speak, to modulate intonation, to behave in a certain way, to adopt specific mimics, gestures and attitudes, to choose an attitude, to prepare combined actions, to develop physical or normative devices, to act on the elements of the environment ... everything to solve as much as possible a problem related to a fact of life [2].

The communication process is based on establishing a relationship between a transmitter and a recipient. A transmitter wishing to provide information will have to translate it in a language accessible to the recipient and compatible with the means of communication used: this is coding. Thus elaborated, the message is delivered and circulated through a material support: the communication channel. It then reaches the receiver-recipient, which, through a decoding activity, will acquire and understand it. To be truly effective, the system involves a way of controlling, adjusting, and correcting mistakes: this is feedback, in other words, the loopback from the receiver to the transmitter [3].

In Basketball, the referee is surprised in various communication situations. $\mathrm{He}$ sends a message, from one side to the other, able to set forth the process very clearly and simply through the following Shannon's graphical scheme, which appeared in the context of cybernetics and has great popularity and a real success:

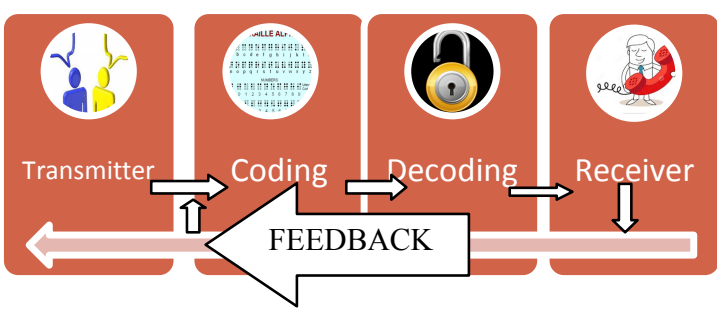

Figure 18.Communication scheme (afterShannon)

Therefore, for us,we might say that communication is knowing or bringing an 
idea, action or phenomenon onto light; there may also be the verbal contact within the group in which we act.

\section{Semantic and ectosemantic language}

On a socio-professional basis, the basketball referee has a general type of communication (similar to other people) with his colleagues, members of the Central Board of Referees, coaches, media, players and spectators.

The referee's communication system is a complex one, and in order to be ideal, we organize it into the following scheme:

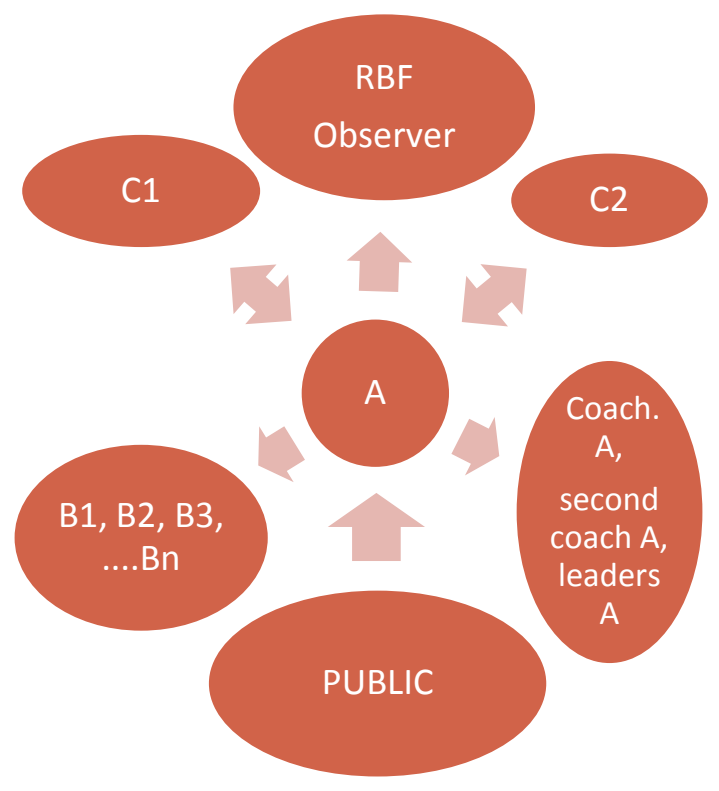

Figure 19.The ideal communication system of the basketball referee

(A-referee, C1, C2- his partners, A1, A2, B1, $B 2$ - players of the two teams, antr. $A, B$ coaches and leaders of the two teams)

If we carefully observe the above scheme regarding the establishment of an ideal communication system between the basketball referee and the other players in a sports competition, we can uncover the following ideas:

$>$ Communication between referee A and his other two colleagues is strong and reciprocal;

$>$ Communication between referee A and RBF observer is a two-way communication, but it is not as strong as communication with the two colleagues in the field;

$>$ The communication between referee $\mathrm{A}$ and the other players of the game, the players, the coaches, the leaders of the two teams are mostly short and focused on clear elements of the regulation or its interpretations;

$>$ Communication with the public is indirect, and we notice that only the latter can communicate to the referee.

In many situations there are reactions to disapproval, contestation, vehemence, and even violence, in relation to the referee's decisions, which makes the scheme outlined above totally different from the real one.

Discrete touch line vectors, from coaches, players and the public, take a strong tinge towards the referee. Violence scenes against the referees were reported mainly in football and hockey games, but also in basketball games.

We can therefore see that the quality of the communication has a great influence on the pertinence as well as the quality of the code used, which will be the more effectiveas it will be adapted to the way the information is circulated, the characteristics of the actors directly involved, and the finality of the situation.

We can say that for an optimal communication we need an optimal code, which allows for the best understanding of the transmitted message by the recipient. The code must always be handled according to the receiver. In a communication situation involving the transmission or exchange of information, the code used will be the more efficient as it is less ambiguous [4].

Always, one of the sources of communication difficulties is the ambiguity of the code. The language of the transmitter needs to adapt according to the interlocutor, and this phenomenon occurs spontaneously and even from the youngest.

Very important in communication is the order of words. In assigning the 
information, this can play a very important role. It has been observed that the first words are more valorized in relation to those that succeed them, phenomenon explained by the primacy effect [5].

Therefore, the referee has to communicate very well and with great care to be understood and in order for his code to be received by those with whom he enters into direct contact. The time he has is not long, but the message must reach the recipient in the best shape. He has to use short and precise sentences, quick and direct answers.

Communication has three elements of content, namely verbal, voice and gesture communication. The verbal element is the set of words that makes up their message, their phrases and their turn, the syntax etc.; the vocal tone - the tone on which these words are spoken, the different information that the voice adopts to make their message. As for the visual element, it sums up everything people see, that is your physical appearance (sex, nationality, age, clothing etc.) as well as all your gestures, postures and mimics [6].

Actors in communications, especially in the field of ump rage, pay great attention to gesture language, so we need to be aware of the impact of our moves and attitude on the ground over all participants in the sports events. We must accurately state what we want to convey so that we can express ourselves the best possible.

In order to establish balanced and longlasting relationships, we must learn to respect the other interlocutors as well as their territories and areas. The territory of a man is the place where he leaves his hallmark, and this failure can lead to conflicts and misunderstandings.

In order to better understand the feature of "areas" in communication, we can divide them as: the intimate area, the private area, the social area and the public area.

An American anthropologist, Edward Hall, is the one who first established that the human being moves within four distinct areas. Knowledge of these areas is essential if we want to evolve harmoniously in society. Failure to do so risks not only to engage to our interlocutors a reflex of mistrust often followed by a rejection, but also to expose ourselves to the judgments of our peers regarding our education [7].

The intimate area is the area in the immediate vicinity of our body, namely the "aura" that some scientists speak of. It is an area of energy, a sphere of protection and it is our protection like a shield or a wall. As soon as this zone is exceeded without permission, a pressure that both activates and increases adrenaline levels, increased heart rate, blood pressure, and a defensive attitude with the whole body is triggered within us. We need to be aware of the size of this area, approximating that it is between 15 and $45 \mathrm{~cm}$.

Due to the fact that it is a very sensitive area, we cannot let anyone in this area or make our presence felt in other people.

In ump rage, we need with much training and practical experience to have selfmastery and to understand this more than anyone else.

The actors of the sports show we are part of can be often bitter, irritated and excited because of the outcome of the game or the way the game is played. For this reason, we cannot afford any such mistake, the intrusion into their intimate area, or the coaches in order not to give rise to new conflicts. But at the same time, we must not allow them to violate our intimate area in an attempt to intimidate us. We must remain masters of the situation and our own emotions. We need to know how to diminish them and how we get to think correctly and for the benefit of the game we arbitrate.

Even if it does not possess the rigorously intimate character of the previous area, the private area is still a personal space. The distance in this case varies from $45 \mathrm{~cm}$ to $1.20 \mathrm{~m}$. It is the space that we ought to leave between us and others when we evolve in society. It is also the distance they keep between each other to converse, 
work colleagues, friends, neighbors, friends of your friends, in short, all the people with whom you share a bit of your daily life, other than in strict privacy [8].

In ump rage, we can use this area to explain or listen to certain questions. We have to be realistic and understand that in a 4000-room audience in which everyone encourages their favorite team, we can not communicate through verbal language from a very long distance. Then we enter into communication with the other participants in this area, the private area, but it is very important not to overcome it, not to exceed it.

The social area corresponds to the sum of two private areas and is known as the convenient and common sense distance to be kept between two foreign persons [9].

This area is mainly used in relationships with strangers, or in our field of media relations, or spectators.

There is also the public area, but we do not use it that much in umpirage. The public area is beyond the social area. It is generally the privileged area of the orators that address a large crowd or audience. Usually, speakers who address small groups will prefer the social area because it has the merit, if not to create close links, at least to favor a synergy effect between the speaker and the audience [10].

\section{Language in communication}

To communicate in any form, we need language. It can be defined as: a communication system made up of articulated sounds, specific to people, through which they express their thoughts, feelings and desires; language, speech; a specific way of expressing feelings and thoughts in the common or national language, a way of expressing itself simply, undemanding; common language; means, basis of understanding; means of expressing ideas or feelings through color, musical sounds etc., [11].

What is Semantic Language? It is that language that refers to the meanings of words, as well as to their evolution.
According to the great Neologism Dictionary, it is an ensemble of words in a close correlation of sense; a branch of linguistics that studies the meanings of words and their evolution over time; part of semiotics studying the ratio of signs to designated objects; it is the theory of interpreting a formal system formalized by another formalized system [12].

This language can be expressed in spoken or written language, communication is relatively easy because the transmitter and receiver (receivers) have a common, rather important, repertoire.

The referee frequently uses this type of communication in his professional relations with the Central Referee Board, with his colleagues in the field, with the RBF observer appointed for competitions. He uses this language but to a lesser extent also with the players and coaches.

In the competition itself, this language is used to a small extent, approximately $5 \%$, of the total means of communication between the referee and the other protagonists.

The official language of communication in the grand family of basketball is English and the referees must know it, at least at the conversational level. International referees need more than that because they are subject to language tests that bring them to some specific terms, both in basketball and in ump rage.

What is ecto semantic language? It is known as generic nonverbal language, it is the language of body and emotions.

In ump rage, it is expressed by signaling, codes, gestures; it is understood by those who have been informed, by the protagonists of the sports show, having a common repertoire, which belongs to the basketball game. This language is internationalized, making the globalization of the game and its specific signs swift and permissive.

Like musicians, or plastic artists, the language of basketball referees' own language is well understood on all the meridians of the civilized world. 
In order to better understand these signaling we will describe them in what follows, as they are presented in the Basketball Game Rules.

Communication science takes on its own the essential idea that the meaning arises from the realization of a relation between communication and the situation in which communication is made. The sense therefore appears in a contextualization.

Any situation in which we find ourselves can be decomposed into several contexts, as in a context overlap .

These contexts have been defined as:

$>$ The spatial context, i.e. everything is regarded in a certain way, depending on the place and its characteristics;

$>$ The physical and sensorial context, everything we express acquires a certain characteristic and sense in relation to the sensory components, in ump rage, especially the visual and auditory;

The temporal context, everything we convey has a certain connection with what has been previously transmitted, with us being the lapidary explanations from the context of the games transmitted to our players, coaches and colleagues;

$>$ The context of the positioning of the participants; everything we transmit has a certain value and a certain meaning, depending on the links and relationships that exist between the subjects of the communication;

$>$ The cultural context, what we convey is related to everything we invoke during the communication and the links that are created between the transmitted elements;

$>$ The expressive context refers strictly to everything we express and to everything that comes into play by the actors involved.

Referring strictly to the direct interest in communicating basketball players, we begin to look at what happens when communicating between the participants' relationships and their approximate positions. In communication there is a great emphasis on the place occupied by the interlocutors. "In the communication process, the speaker's activity is not limited to issuing the message [13]. The speaker issues judgments, and skillfully gives his interlocutor various places.

The place in a communication is different from the role of the interlocutors or their status; it is "the identity the speaker assumes in the context of communication and his interlocutors, here and now, depending on his intention to communicate and how he presents the stakes of exchange [14]

In terms of the context of relationships, we can say that when communicating, certain relationships and reports are established with that person or with those individuals. The relationships and connections between the actors of communication are classified according to their quality, which can come from total disagreement, agreement, passing through the equidistant state of the actors. Also, these relationships are in close connection with the interlocutors' feelings of sympathy and antipathy towards each other. The relationship between the interlocutors is precisely established throughout the communication and may undergo subordinate quality changes and interaction among the actors. In our work the communication that is established between the actors in the competition and the touching of the interlocutors or the creation of emotional proximityis also very important. Due to the fact that we are more than accustomed to touching only those who are very close to us, this gesture is the "transcultural sign of approaching that person: touching an individual's arm is a gesture that reminds of this proximity rule. If he does not withdraw his arm, this means he is accepting the new relationship we suggested [15].

\section{Conclusions}

Due to the fact that we were able to combine scientific and direct science 
documentation, we have achieved the objectives we have proposed:

$>$ Analysis and evaluation of the information from the field specialists;

$>$ Researching the favorable trends underlying the improvement of basketball umpirage;

$>$ Observing the factors that have acted upon umpirage over time;

$>$ Studying the directions of development of contemporary umpirage.These results lead to the conclusion that there is a deficient implementation of the referee and basketball umpirage theory. Starting from this premise, it is advisable to conduct a study, first on the desire of specialists in the field, to change something and then to observe and effectively record the data coming from the tests.

Hoping that what we have presented will find an echo in the next work, the effort of all can only be directed to the desire of everyone to feel satisfied and reconciled only to what he has accomplished, we will succeed together with all the federation's responsibility to contribute to the maintenance ofdiscipline in the sport we all love, the improved affirmation of the Romanian basketball on the level of the European values and, why not, even the world.

\section{References}

[1] Abric, J. C., Psihologia comunicării, Bucureşti, Editura Polirom, 2002, p.14

[2] Mucchielli, A., Les situations de communication, Paris, Eyrolles, 1991, p. 94

[3] Abric, J. C., op.cit., p.14

[4] Abric, J. C., op.cit., pp 25-26

[5] Abric, J. C., op.cit, p. 27

[6] Cameron, M., Comunicarea prin gesturi şi atitudini, București, Editura Polirom, 2005, p. 10

[7] Cameron, M., op.cit., p.15

[8] Cameron, M., op.cit., p.19

[9] Cameron, M., op.cit., p. 20

[10] Cameron, M., op.cit., pp 21- 22

[11] Dicţionarul Explicativ al Limbii Române, ediţia aII-a, București, Editura Univers Enciclopedic, 1998, p.75

[12] http://dexonline.ro/surse(MDN)

[13] Agnoletti, M., F., citat de Mucchielli, A., Arta de a influenţa, București, Editura Polirom, 2002 p. 61

[14] Mucchielli, A., op. cit., p. 61

[15]Mucchielli, A., op. cit., p. 94 